\title{
Isolation and Expression Analysis of Floral Binding Protein 20 (FBP20) MADS Box Gene in Petunia axillaris
}

\author{
Shilpy Singh, VivekRana, Pushpendra Kumar", Manoj Kumar Yadav and Vaishali \\ Department of Agricultural Biotechnology, Sardar Vallabhbhai Patel University of \\ Agriculture and Technology, Meerut, U.P.-250110, India \\ *Corresponding author
}

\section{A B S T R A C T}

\begin{tabular}{|l|}
\hline Ke y w o r d s \\
MADS Box \\
transcription factor, \\
Petunia axillaris, \\
Nicotianatobacum, \\
Flowering, Floral \\
binding protein 20, \\
SOC1 \\
\hline Article Info \\
\hline Accepted: \\
14 December 2018 \\
Available Online: \\
10 January 2019
\end{tabular}

Keywords

MADS Box transcription factor Petunia axillaris, Nicotianatobacum, owering, Floral $\mathrm{SOCl}$

Introduction

Petunia is a popular bedding plant that has a long history as a genetic model system. The genus Petunia is a member of Solanaceae family and is native to South America. Bombarely et al., (2016) reported the estimated size of petunia genomes is $1.4 \mathrm{~Gb}$ and chromosome number is $2 \mathrm{n}=14$. The petunia is used as a model plant for flower development and pigment synthesis along with other flower characters. The phenomenon of co-suppression was just reported in petunia by Napoli et al., (1990) in their experiment of higher anthocyanin synthase gene for higher pigment synthesis in petals.

MADS Box genes are the key players and can be characterised as the architects of flower development. The name MADS Box was proposed by Schwarz-Sommer and colleagues (Yanofsky et al., 1990) and derives from the initials of the first four cloned genes. Minichromosome Maintenance 1 (MCM1) factor in Saccharomyces cerevisiae (Passmore 
et al., 1988), AGAMOUS (AG) in Arabidopsis (Yanofsky et al., 1990), DEFICIENS (DEF) in Antirrhinum (Sommer et al., 1990) and Serum Response Factor (SRF) in humans (Norman et al., 1988). MADS Box gene family divided into two lineages i.e. type I and type II. Plant type I MADS domain genes can be further subdivided into three groups: $\mathrm{M} \alpha, \mathrm{M} \beta$ and $\mathrm{M} \gamma$ based solely on phylogenetic criteria (Bemer et al., 2010) while, in the case of Type II genes, MIKC ${ }^{\mathrm{C}}$ and MIKC*-group genes are distinguished by different lengths of their encoded K-domains and also on phylogenetic criteria (Kwantes et al., 2012). Type II MADS-box proteins are commonly referred to as MIKC-type proteins based on their domain structure, which comprises the highly conserved MADS-domain (M), a moderately conserved intervening (I) domain, a wellconserved keratin-like (K) domain and a highly divergent carboxy terminal (C) domain (Smaczniak et al., 2012). All MADS- Box genes possess a highly conserved 180bp DNA sequence, that MADS-Box is required to encode the DNA-binding domains (Kaufmann et al., 2005). Plants MADS-Box genes can bind the DNA as homodimers, heterodimers or higher-order complexes. Dimers of MADS domain transcription factors bind to the consensus sequence $5^{\prime} \mathrm{CC}$ [A/T] 6GG-3'(or similar) called the CArGbox, to regulate transcription of target genes (Theißen and Gramzow, 2016).

The petunia genome contains three SOC1 (SUPRESSOR OF OVEREXPRESSION OF CONSTANTS 1) homologs - UNSHAVEN (UNS)/FLORAL BINDING PROTEIN 20 (FBP20), FBP21, and FBP28 - derived from two duplication events within the Solanaceae. All three genes are strongly expressed in leaves (Immink et al., 2003) and at least UNS is expressed in vegetative apices, with expression becoming reduced following the transition to flowering (Ferrario et al., 2004).
However, constitutive expression of UNS in petunia and FBP21 in tobacco causes early flowering under short days, bract-like petals, and hairy ovaries (Ferrario et al., 2004), and accelerated flowering under long days, reduced plant height and leaf size, and increased flowering branches ( $\mathrm{Ma}$ et al., 2011), respectively. The late flowering phenotype of both species suggests that UNS and FBP21 promote the transition to flowering similar to Arabidopsis thaliana SOC1 (Samach et al., 2000).

UNSHAVEN (UNS) is a member of the SOC1-like gene group from Petunia hybrida. Previous work has shown that UNS is down regulated upon floral initiation and formation of floral meristems (Ferrario et al., 2004). FBP21 is another SOC1- like gene from Petunia, which shares high sequence similarity with UNS (Immink et al., 2003). Expression levels of the SOC1-like genes UNSHAVEN (UNS) and FLORAL BINDING PROTEIN 21 (FBP21), but not FBP28, are positively correlated with developmental age. The data suggest a conserved role for all three genes in the promotion of flowering (Preston et al., 2014).

In present study, the isolation of Petunia axillaris FBP20 MADS box gene will be workout to assess the role of this gene with molecular perspective in flowering. Our aim to contribute a better understanding of MIKCtype MADS box genes and function using Petunia axillaris. Here, we report the isolation and expression analysis of FBP20 MADS box gene from different parts of Petunia axillaris plant.

\section{Materials and Methods}

\section{Plant materials and growth conditions}

Petunia seeds were collected from Department of Horticulture of SVPUA\&T, 
Modipuram, Meerut. Plants were raised in the field laboratory of Department of Agriculture Biotechnology of SVPUA\&T for collecting the tissue samples of different parts of Petunia axillaris plant.

\section{Data mining and designing of FBP20 gene specific primer}

The publicly available gene sequence of Petunia was searched for FBP20 from NCBI database (ftp://ftp.ncbi.nih.gov/blast/db/). The assembled sequences were searched for identification and localization of forward and reverse primers from the flanking sequences. The primers were designed using online available software.

\section{Isolation and Cloning of the FBP20 cDNA from Petunia axillaris}

Total RNA was isolated from leaves, Sepals, Petals and flower buds of Petunia axillaris using Gene JET Plant RNA Purification Mini Kit (Thermo Scientific). The reaction mixtures for cDNA synthesis were prepared using cDNA direct ${ }^{\mathrm{TM}}$ kit $\left(\mathrm{GeNei}^{\mathrm{TM}}\right.$, Bangalore).

The FBP20 full-length gene was obtained by PCR amplification from a Petunia flower bud cDNA using FBP20 gene-specific primers (forward primer: 5'- ATGGTGAG GGAAAAACTC-3'; reverse primer: 5'CACCAATTAATTCTGTAAGCG-3'). The PCR amplification was carried out using with the following cycling parameters: heating for 3 min at $94^{\circ} \mathrm{C}$, total 40 cycles of denaturation at $95^{\circ} \mathrm{C}$ for $1 \mathrm{~min}$, annealing for $30 \mathrm{~s}$ at $49^{\circ} \mathrm{C}$, synthesis for $1 \mathrm{~min}$ at $72^{\circ} \mathrm{C}$ and extension at $72^{\circ} \mathrm{C}$ for $10 \mathrm{~min}$. The gene fragment of around $651 \mathrm{bp}$ was obtained and cloned into the pGEM-T Easy vector (Promega), and confirmed by sequencing.

\section{Sequencing and phylogenetic analysis}

Two clones of FBP20 gene were sequenced in both the directions (with SP6 and T7 universal primers). The sequencing was carried out at the DNA sequencing facility, Eurofins Genomics. The nucleotide sequences were subjected to BLAST analysis (http://www.ncbi.nlm.nih.gov/blast/) to confirm the sequences thus generated are of petunia genome.

Sequences generated were trimmed and assembled manually to retain only the coding regions of each gene by removing vector sequences as well as the nucleotide sequences flanking the protein coding regions. The fragment obtained after trimming was somewhat similar to some of the SOC1 ortholog. The phylogenetic tree was constructed with the Neighbor-Joining algorithm using the software MEGA 7.0 (http://www.megasoftware.net/).

\section{Expression analysis}

Total RNA extracted from Petunia axillaris samples (leaf, Sepal, Petal and Flower bud) served as the template for first-strand cDNA synthesis using the using cDNA direct ${ }^{\mathrm{TM}}$ kit (GeNei $^{\mathrm{TM}}$, Bangalore). For semi-quantitative RT-PCR analysis of FBP20 expression in Petunia axillaris plants, FBP20 was detected with the primers Forward 5'ATGGTGAGAGGAAAAACTC-3' and Reverse 5'-CACCAATTAATTCT GTAAGCG-3', while the $\beta$-Actin gene was amplified as a control with the primers Forward 5'-ACCACAGGTATTGTGTTGG ACTC-3' and Forward 5'-AGAGCATATCCT TCATAGATG GG-3'.

The Petunia $\beta$-Actin gene was used as the normalization controls for expression analyses in Petunia. For all genes tested at different cycles as 23cycle, 27cycle, 31cycle, 
35 cycle and 40cycle were optimal for the expression. Recipe of reaction mix used for PCR amplification were same and electrophoresed on $1.5 \%$ agarose gel. The PCR amplification was carried out using with the following cycling parameters: heating for 3 min at $94^{\circ} \mathrm{C}$, total 40 cycles of denaturation at $95^{\circ} \mathrm{C}$ for $1 \mathrm{~min}$, annealing for $30 \mathrm{~s}$ at $49^{\circ} \mathrm{C}$, synthesis for $1 \mathrm{~min}$ at $72^{\circ} \mathrm{C}$ and extension at $72^{\circ} \mathrm{C}$ for $10 \mathrm{~min}$. The housekeeping gene $\beta$ Actin was selected as an internal quantitative control.

\section{Protein secondary structure analysis}

The secondary structure prediction of our protein FBP20 was computed by using various online softwares, which included RaptorX. The RaptorX is a protein structure prediction server which was used to predict secondary structures (Källberg et al., 2012), excelling at predicting 3D structures for protein sequences without close homologs in the Protein Data Bank (PDB).

The FASTA sequences of our proteins were retrieved after sequencing and were submitted to the RaptorX server. Using RaptorX server, number of secondary structure components such as $\alpha$-helix, $\beta$-sheets, turns, random coils were predicted.

\section{3-D structure analysis of protein}

The molecular modelling of our proteins FBP20 was carried out using multiple Protein Homology structure prediction servers. The best results were found in PHYRE2 with the highest query sequence coverage and confidence (Kelley et al., 2015). The best template which provided the maximum query coverage and confidence based on the ranking of raw alignment score was selected. The modelledFBP20 was shown using RasMol software.

\section{Results and Discussion}

Isolation, cloning and sequencing of FBP20 from Petunia axillaris

The FBP20 gene was isolated from the cDNA flower bud of Petunia axillaris. PCR was carried out using FBP20 gene specific primer for amplification of FBP20 gene. A coding region of around $651 \mathrm{bp}$ was amplified and visualized in the $1 \%$ Agarose gel electrophoresis (Fig. 1). The PCR product of FBP20 gene was eluted and cloned in pGEMT cloning vector, and several transformed clones were confirmed by blue white screening. Thereafter by colony PCR (Fig. 2) as recombinant clones using the FBP20 gene specific primer following standard protocol (Sambrook and Russell, 2001). After colony PCR, the colony showing positive result was used for Plasmid isolation and Restriction digestion of the plasmid with NotI to confirm that the plasmid contained the FBP20 gene (Fig. 3). After confirmation of recombinant clones, two clones were sequenced using the vector derived primer in automatic sequencer and presented in Figure 4A. On the basis of sequence analysis we find that there were slight changes in nucleotides and amino acid sequences of MADS Box domain of isolated FBP20 gene from Petunia axillaris and FBP20 gene of Petunia hybrida as shown in Figure 4B and 4C i.e. the change in four amino acid residues Lysine $(\mathrm{K}$; nine) in place of Arginine (R), Glycine (G; ten) in place of Arginine (R), Valine (V; eleven) in place of Isoleucine (I) and Glycine $(\mathrm{G}$; twelve) in place Glutamic acid (E). The other domains of FBP20 gene i.e. the K-box domain and SOC1 motif have similar sequences and are highly conserved.

\section{Phylogenetic analysis}

Phylogenetic analysis with 23 sequences of MADS genes from other species were 
performed using neighbor- joining (NJ) method. The bootstrap values of the phylogenetic trees were derived from 1000 replicates run. A phylogenetic treeis constructed using full-length amino acid sequences based on the analysis of the MIKC group MADS Box gene was constructed to determine the evolutionary relationship between Petunia axillaris FBP20 and other SOC1-like proteins. The tree showed that FBP20 was included in SOC1 clade with its orthologs, such as IbAGL20, Ipomoea batatas; TobMADS, Nicotiana tabacum; PhFBP20, PhFBP21, PhFBP22, PhFBP28, Petunia hybrida; RpSOC1, Rhododendron pulchrum; GmSOC1, Glycine max; AtSOC1, AtAGL14, AtAGL19, AtAGL42, AtAGL71, AtAGL72 Arabidopsis thaliana; SISOC1, Solanum lycopersicum; AaSOC1, Arabis alpina; MtSOC1, Medicago truncatula; VvMADS8, Vitis vinifera; GhGSOC2, Gerbera hybrida; PmSOC1, Plantago major; AmDEFH68, Antirrhinum majus; DSOC1, Dendrobium sp. All the genes used with their GenBank accession numbers and respective species were listed in Figure 5.

\section{Expression analysis of FBP20 gene in floral organs}

MADS-box genes participate in various processes of plant growth and development. To know more about the expression pattern and function of FBP20 MADS Box gene, the expression of FBP20 in various tissues of Petunia axillaris i.e. in leaves, Sepals, Petals and flower buds by semi-quantitative PCR were examined. The gene expression analysis was carried out at different PCR cycles 23, $27,31,35$ and 40 to compare the transcript abundance of FBP20 in different tissues. $\beta$ Actin was used as housekeeping gene for the normalization of the cDNA. In semiquantitative PCR, a target cDNA species was amplified using the same number of cycles for all investigated samples. After electrophoretic separation in a gel and staining with $\mathrm{EtBr}$, the expression rate of the target gene is assessed by measuring the intensity of the band corresponding to the generated amplicon. The band intensity reflects the number of copies of the target cDNA at the beginning of the PCR, and thus the level of expression of the target gene in the sample. To ensure that the analysis yields reliable results, the concentration of total cDNA must be the same in all of the samples analysed. Each cDNA sample was, therefore, initially diluted until the intensity of the band corresponding to a $\beta$-Actin gene obtained from each sample was the same after a defined number of PCR cycles. FBP20 transcripts were detectable at low levels in vegetative tissues, such as leaves, whereas its expression in reproductive organs, such as in floral buds significantly increased. The expression of FBP20 gene in the petals was not detectable, which may be attributed to the fact that their expression was too low to be detected or no expression at all. In this leaf tissue shows band of FBP20 at 35 cycles, Sepals shows band at 40 cycles, in petals no expression was detectable and in flower bud expression was detectable at 31 cycles. The expression level of FBP20 gene was 32 and 16 fold higher in flower buds than that sepals and leaves respectively (Fig. 6). These results indicate that FBP20 function might be closely associated with the reproductive development of Petunia axillaris.

\section{Secondary structure analysis and functional characterization}

On the basis of alignment of our query protein i.e. FBP20 which was isolated from Petunia axillaris with FBP20 protein of Petunia hybrida from NCBI we find that there were slight changes in the MADS Box domain of our query protein. Secondary structure of MADS Box domain of these proteins were predicted using RaptorX. Secondary structure prediction is provided in 3 state secondary structure modes, which represent helix, beta- 
sheet and loop (disordered) (Fig. 7). When we compare the secondary structure of MADS Box domain of these proteins we find that there were changes of two amino acids in $\beta$ strand i.e. Lysine ( $\mathrm{K}$; nine) in place of Arginine (R) both amino acids are positively charged and have polar side chain so they are functional similar and the other Glycine $(\mathrm{G}$; ten) in place of Arginine (R) these two amino acids are different i.e. one has non-polar side chain and the other has polar side chain. The other two amino acid changes in disordered structure (loop) i.e. Valine (V; eleven) in place of Isoleucine (I) these amino acid are non-polar and hydrophobic in nature and the other Glycine (G; twelve) in place Glutamic acid (E)these two amino acids are different i.e.one is non-polar and the other is negatively charged polar amino acid.

\section{3-D structure analysis of protein}

Our query protein FBP20 was subjected for modelling using PHYRE2 ((Protein Homology/AnalogY Recognition Engine). Phyre2 is a major update to the original Phyre server with a range of new features; accuracy is improved, using the alignment of hidden Markov models via HH search to significantly improve accuracy of alignment and detection rate. The modeled structure of MADS Box domain of our query protein FBP20 and the FBP20 Petunia hybrida protein were viewed in RasMol tool (Fig. 8). On the basis of these structure we find that both belongs to SRF (Serum Response Factor) like transcription factor family.

Fig.1 PCR amplification of FBP20 Petunia axillaris samples from different tissue cDNA: Lane M: 100bp DNA Ladder, GeneRuler (Fermentas); Lane 1:Leaf; Lane 2: Flower bud; Lane 3: Sepal; Lane 4:Petal

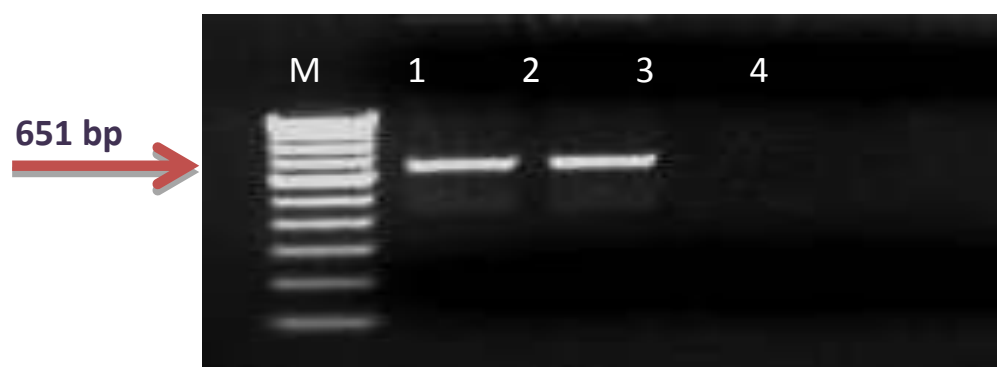

Fig.2 Colony PCR amplification of FBP20 from pGEMT vector transformed in DH5 $\alpha$ cells. Lane M: 100 bp DNA Ladder, GeneRuler (Fermentas); Lane 1-3: three colonies grown on antibiotic media; Lane 4: Positive Control; Lane 5: Negative Control

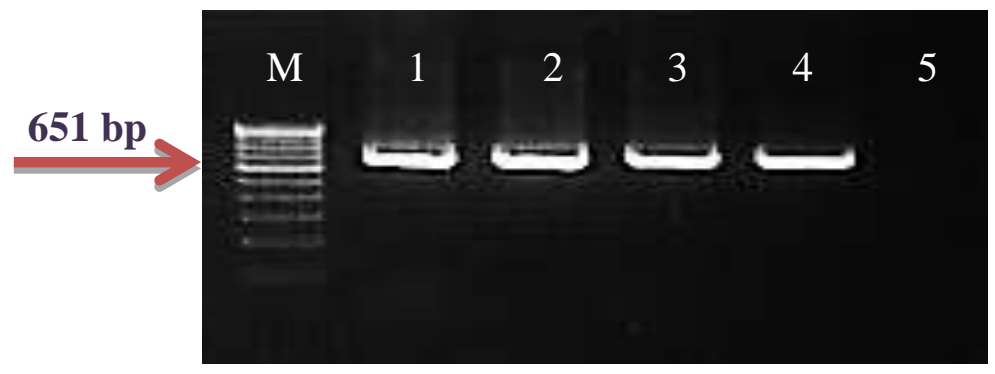


Fig.3 Restriction Digestion of FBP20: Lane 1-3: Restriction release of Full FBP20 with NotI from pGEMT cloning vector; Lane M: 1Kb DNA Ladder, GeneRuler (Fermentas)

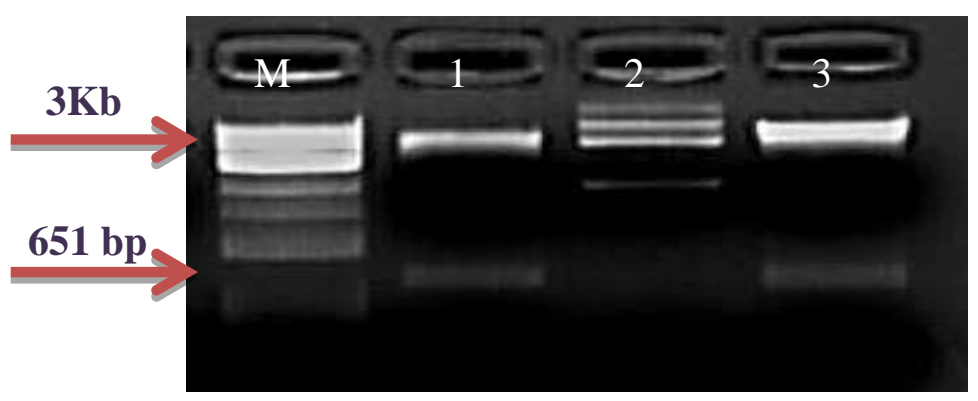

Fig.4A FLORAL BINDING PROTEIN 20 (FBP20) gene nucleotide and amino acid sequence after Sequencing

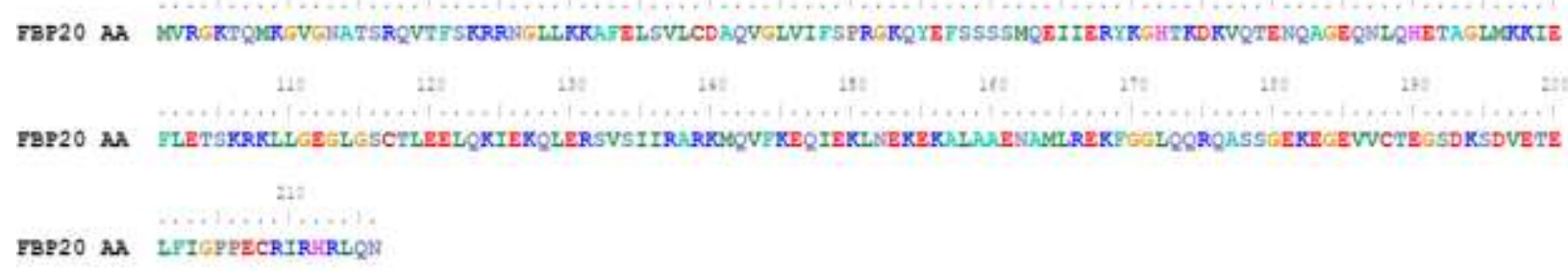

Fig.4B Alignment of the nucleotide sequence of Petunia axillaris FBP20 after sequencing withPetunia hybridaPhFBP20using BioEdit software version 5.0.9. The alignment shows few changes in the number of nucleotides. The nucleotide sequences of PhFBP20 gene aligned in this study was retrieved from NCBI

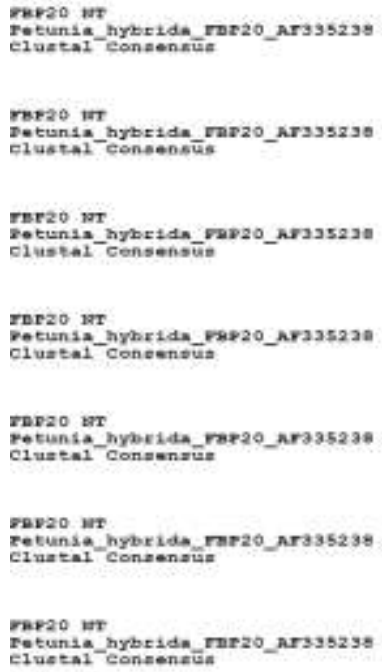

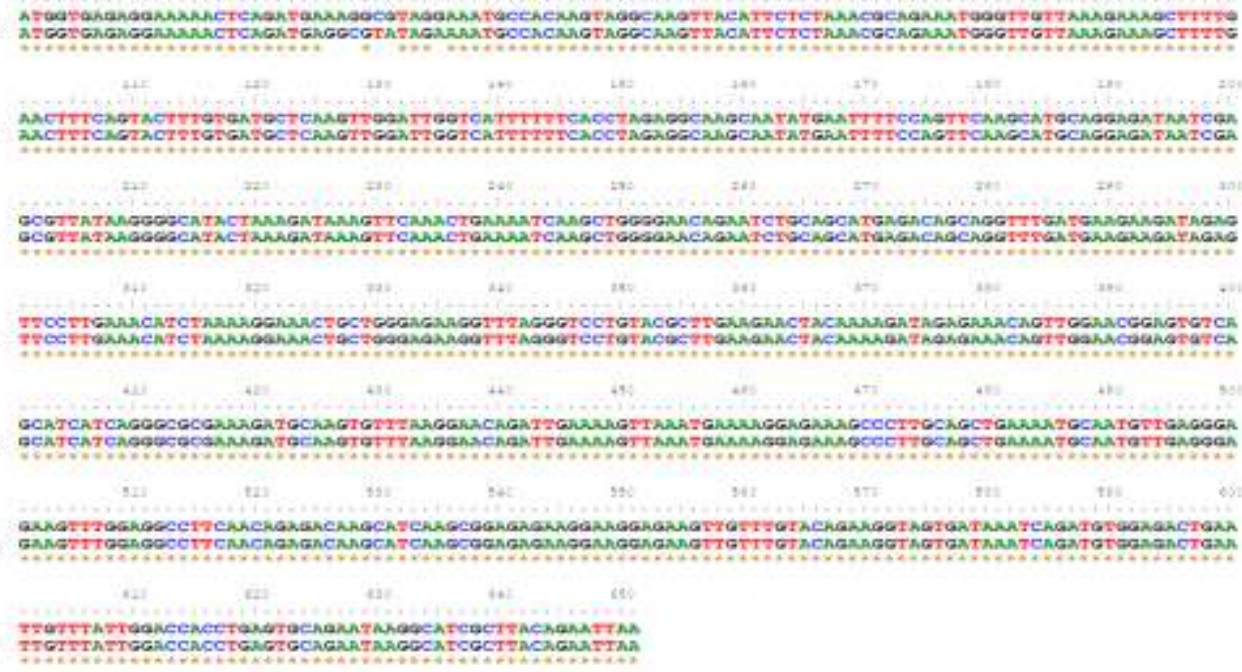


Fig.4C Alignment of the amino acid sequences Petunia axillarisFBP20 after sequencing withPetunia hybridaPhFBP20using BioEdit software version 5.0.9. The alignment shows few changes in the number of amino acids. The regions of the MADS domain, $\mathrm{K}$ domain and the specific SOC1 domain are underlined. The protein sequences of PhFBP20 gene aligned in this study was retrieved from NCBI

FBP20 Ah Clustal Congensuse
Petunia_bybrida_FaP20_Mar21251

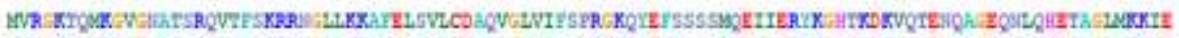

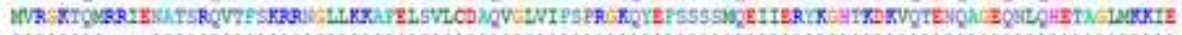

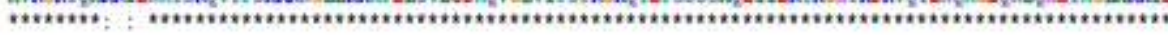

\section{MADS Domain}

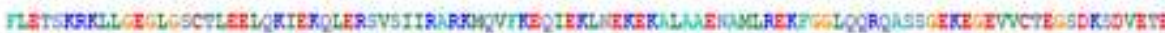

FBP20 AR

Petunia_bybrida_raF20 2ax.21251

c1uatal Consenara

\section{K Domain}

LrTarpchIBHLLC

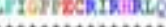

,,,$+ \ldots$,

\section{SOC1 Domain}

Fig 5 Neighbor- joining phylogeny of amino acid sequences SOC1-like genes in petunia and other angiosperms. The tree is rooted on TM3 MADS-box genes in the AGL14/19 clade sister to SOC1/AGL42/AGL71/AGL72 genes (Becker and Theissen, 2003). Bootstrap values (>50\%) in

1,000 replicates are indicated next to the nodes. Genbank accession numbers are shown after each gene name

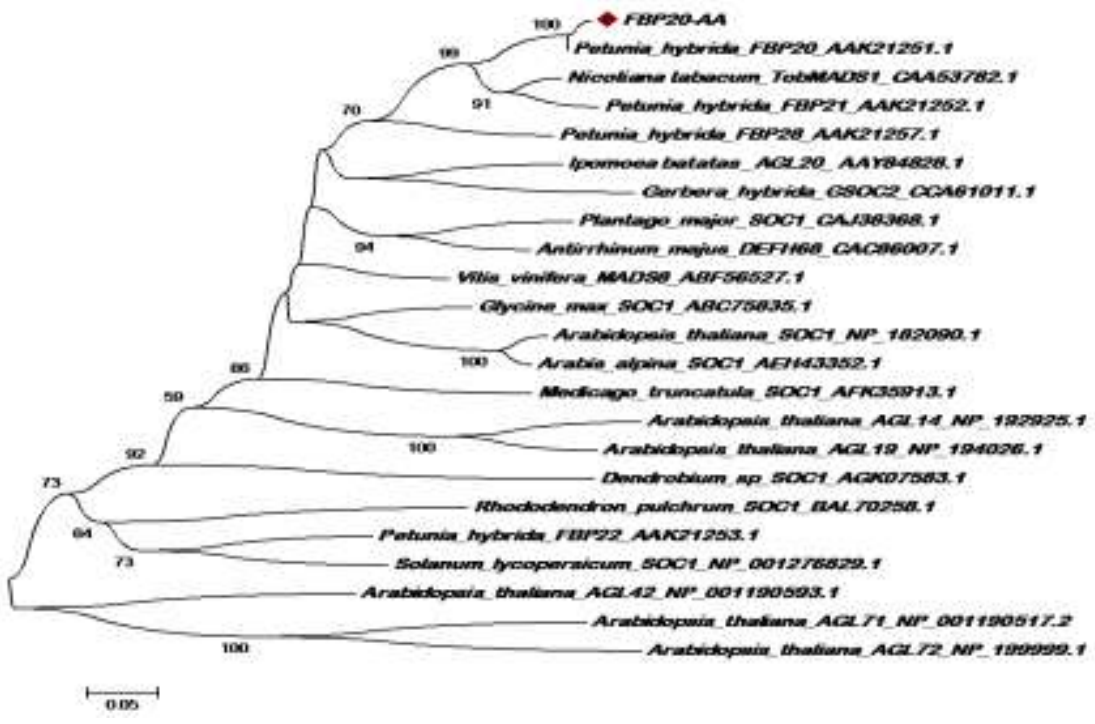


Fig.6 Semi-quantitative Expression analysis of FBP20 MADS genes in different tissues, including leaves, sepal, petal and flower buds isolated from Petunia axillaris. Lane a, b, c, d and e represents PCR cycles i.e. 23, 27, 31, 35 and 40. Leaves, sepal and flower bud expression were detected from 35, 40 and 31 cycles respectively and no detectable expression was showed in petals

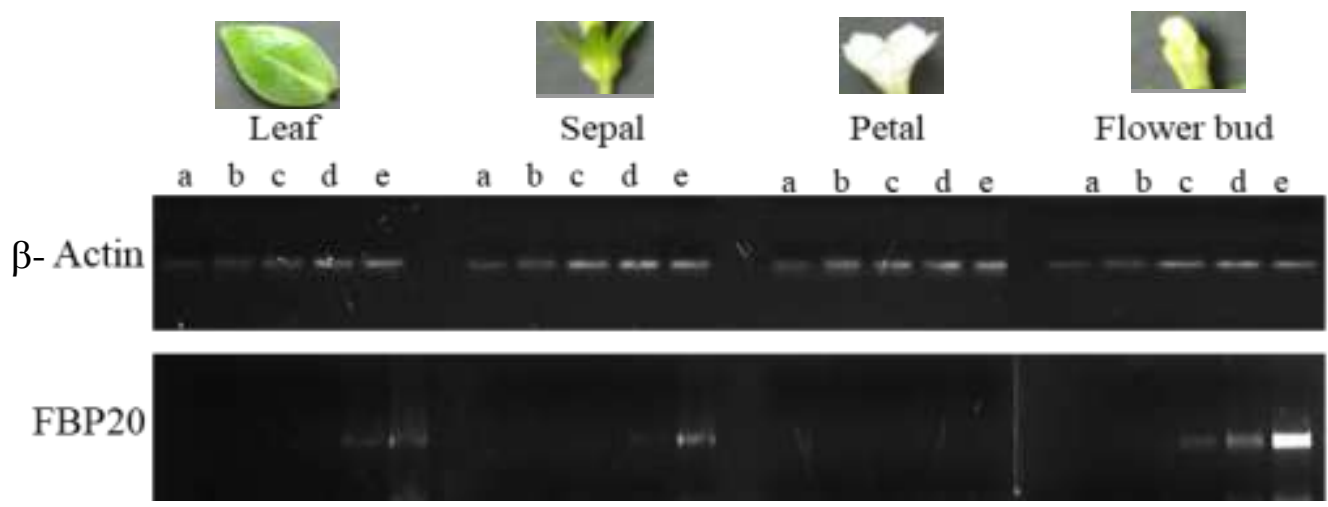

Fig.7 Secondary structure analysis and functional characterization of our protein using RaptorX A. Query sequence of FBP20 gene MADS Box domain isolated from Petunia axillaris; B. Petunia hybrid FBP20 gene MADS Box domain sequence of Petunia hybridaretrieved from

NCBI
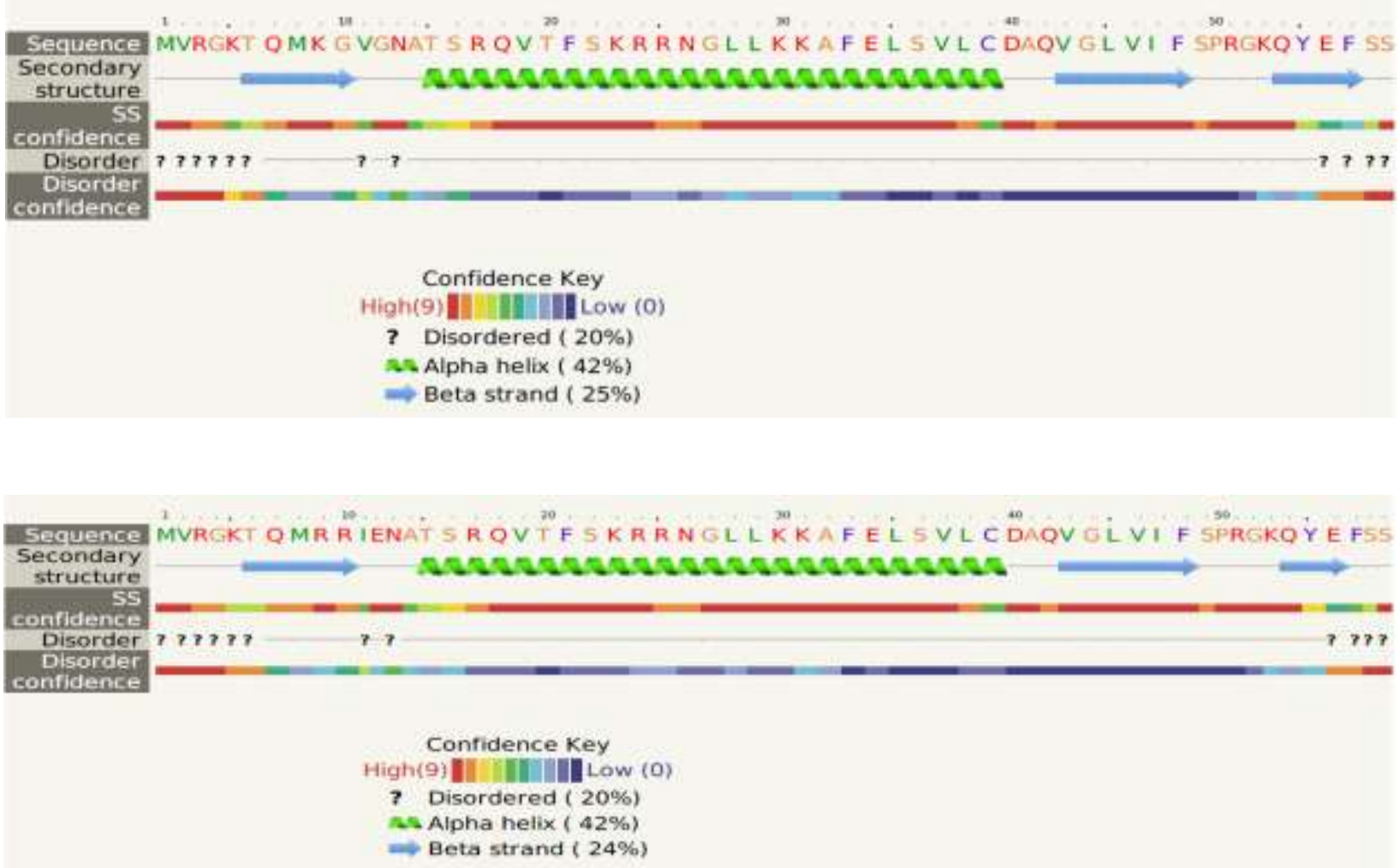
Fig.8 Modelled Structure Generated from Phyre2 Viewed in Rasmol A. Query sequence of FBP20 MADS Box domain isolated from Petunia axillaris B. Petunia hybrida FBP20 MADS Box domain sequence of Petunia hybridaretrieved from NCBI

A

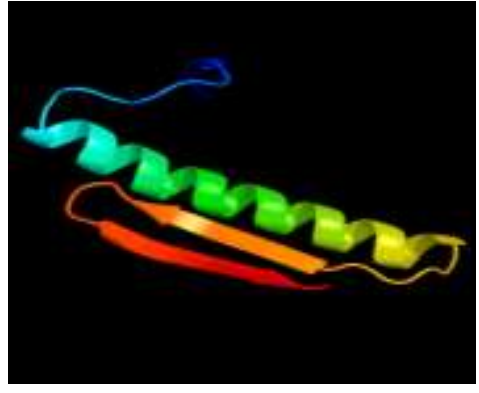

B

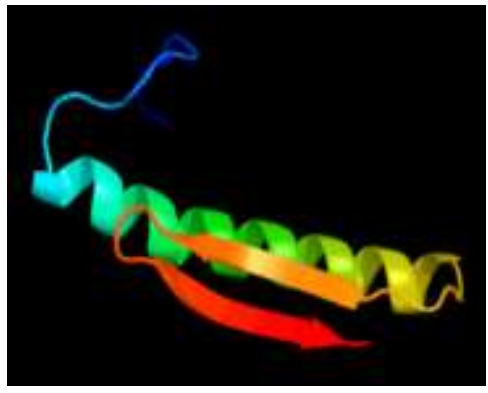

In recent years, more and more studies of the MADS-box family in various species, such as in Arabidopsis (Parenicová et al., 2003), poplar (Leseberg et al., 2006), rice (Arora et al., 2007), grape (Díazriquelme et al., 2008), cucumber (Gan et al., 2012), soybean (Shu et al., 2013), Prunus mume (Xu et al., 2014), apple (Tian et al., 2015), Erycina pusilla (Lin et al., 2015), Brassica rapa (Duan et al., 2015), and radish (Li et al., 2016), have been reported. MADS-box genes in various species showed great difference. The phylogenetic relationships and expression patterns of the different MADS Box genes varied greatly.

When the expression of FBP20was examined, FBP20gene was mainly detected in young floral bud and leaves, relatively weakly in sepals and was completely absent in petals. In addition, FBP20gene was detected at a higher level in young flower buds than in mature flower buds, similar to that observed for AP1orthologsCjAPL2 (C. japonica) and JcAP1 (J. curcas) (Sun et al., 2014; Tang et al., 2016).

In addition, SOC1-like genes may share another function in controlling the life cycle of annual and perennial plants. SOC1 is an important transcriptional regulation factor controlling flowering time (Lee et al., 2004;
Lee, 2010). In Arabidopsis, SOC1 and another flowering time gene, FRUITFULL (FUL), are expressed in inflorescence shoot apices and procambial strands of developing inflorescences, and promote the determinacy of shoot meristems (Hempel et al., 1997; Borner et al., 2000; Lee et al., 2000; Melzer et al., 2008). Three SOC1 genes (DcaMADS14, DcaMADS15, and DcaMADS16) with various expression patterns in vegetative and reproductive organs of carnation. The DcaMADS14 gene was found to be primarily expressed in sepals and DcaMADS15 gene was expressed in all tissues, but show slightly higher expression in stamens and petals than in other tissues. Moreover, the DcaMADS16 gene was only markedly detected in stamen tissues (Zhang et al., 2018). The expression level of A, B, C, D and $\mathrm{E}$ class genes were higher in flower buds than that in stems and leaves, especially the genes DcaMADS27, DcaMADS28, DcaMADS12, and DcaMADS1 (Zhang et al., 2018). Interestingly, SOC1 ortholog, FBP20 shown in this study is expressed in leaves and flower buds, implying that SOC1-like genes could similarly affect the life cycle of many flowering plants.

FBP21 and UNS were classified into the same clade of SOC1-like genes based upon 
phylogenetic analysis (Immink et al., 2003). In fact, the genetic distance between FBP21 and NtMADS1 (a SOC1-like gene from $N$. tabacum) was much closer than that between FBP21 and UNS (Ferrario et al., 2004). FBP21 is functionally active in flowering regulation and plays a significant role in altering the ratio of reproductive and vegetative growth. Based on sequence analysis, FPB21 is suggested to have a role in promoting flowering (Ma et al., 2011). Expression levels of the SOC1-like genes UNSHAVEN (UNS) and FLORAL BINDING PROTEIN 21 (FBP21) and FBP28 suggest a conserved role for all three genes in the promotion of flowering. However, the contribution of each gene to flowering likely varies under different photoperiods and in an age-dependent manner (Preston et al., 2014).

In this study, we have shown that FBP20 exhibits another unique expression pattern, which has not been found for any other SOC1 ortholog. FBP20 is detectable in leaves and sepals but highly expressed in floral buds and no detectable expression seen in petals. The phylogenetic findings suggested that FBP20 is closely related to TobMADS1 transcription factor of Nicotiana tobacuum and FBP21transcription factor of Petunia hybrid might be a promising transcription factor gene for flowering time regulation and act as floral pathway integrator. On the basis of sequence analysis there are a slight changes in nucleotide and amino acid sequence in MADS Box domain of isolated FBP20 from Petunia axillaris and Petunia hybrida FBP20 i.e. the change in four amino acid residues Lysine ( $\mathrm{K}$; nine) in place of Arginine (R), Glycine $(\mathrm{G}$; ten) in place of Arginine $(\mathrm{R})$, Valine (V; eleven) in place of Isoleucine (I) and Glycine ( $\mathrm{G}$; twelve) in place Glutamic acid (E).

It is concluded on the basis of our study we find that the expression level of FBP20 gene was higher in flower buds than that sepals and leaves and no detectable expression was seen in petals. The sequence analysis showed slight changes in nucleotides and amino acid sequences of isolated FBP20 from Petunia axillaris and FBP20 of Petunia hybrida as retrieved from genomic data sequences. On the basis of secondary structure analysis and prediction of MADS Box domain of FBP20 gene showed the changes of few amino acids in both $\beta$ strand and in disordered region. There was neither any changein the 3-D structure nor in the function of MADS Box domain of the protein under study, due to the variations in the amino acid sequence. The phylogenetic findings suggested that FBP20 belongs to SOC1 group of MADS Box family and is closely related to TobMADS1 transcription factor of Nicotiana tobacum which is a promising transcription factor gene for flowering time regulation and act as floral pathway integrator.

\section{Acknowledgement}

We are thankful to the Department of Agricultural Biotechnology, SVPUA\&T, Meerut for providing necessary facilities.

\section{References}

Arora, R., Agarwal, P., Ray, S., Singh, A.K., Singh, V.P., Tyagi, A.K. and Kapoor, S. (2007). MADS-box gene family in rice: Genome-wide identification, organization and expression profiling during reproductive development and stress. BMC Genom. 8: S12.

Bemer, M., Gordon, J., Weterings, K. and Angenent, G. C. (2010). Divergence of recently duplicated Mc-type MADS-box genes in Petunia. Mol. Biol. Evol. 27: 481-495.

Bombarely, A., Moser, M., Amrad, A., Bao, M., Bapaume, L., Barry, C.S., Bliek, M., Boersma, M.R., Borghi, L., 
Bruggmann, R., et al., (2016). Insight into the evolution of the Solanaceae from the parental genomes of Petunia hybrida. Nat. Plants.2:16074.

Borner, R., Kampmann, G., Chandler, J., Gleissner, R., Wisman, E., Apel, K. and Melzer S. (2000). A MADS domain gene involved in the transition to flowering in Arabidopsis. Plant J. 24: 591-599.

Díazriquelme, J., Lijavetzky, D., Martínezzapater, J.M. and Carmona, M.J. (2008). Genome-wide analysis of MIKC-type MADS box genes in grapevine. Plant Physiol. 149: 354369.

Duan, W., Song, X., Liu, T., Huang, Z., Ren, J., Hou, X. and Li, Y. (2015). Genome-wide analysis of the MADSbox gene family in Brassica rapa (Chinese cabbage). Mol. Genet. Genom.290: 239-255.

Ferrario, S., Busscher, J., Franken, J., Gerats, T., Vandenbussche, M., Angenent, G. C. and Immink, R. G. H. (2004). Ectopic expression of the Petunia MADS box gene UNSHAVEN accelerates flowering and confers leaf-like characteristics to floral organs in a dominant-negative manner. Plant Cell. 16:1490-1505.

Gan, D.F. (2012). Genome-wide sequence characterization analysis of MADSBox transcription factor gene family in cucumber (Cucumissativus L.).J. Nucl. Agric. Sci. 26: 1249-1256.

Hempel, F.D., Weigel, D., Mandel, M.A., Ditta, G., Zambryski, P.C., Feldman, L.J. and Yanofsky, M.F. (1997).Floral determination and expression of floral regulatory genes in Arabidopsis. Develop. 124: 3845-3853.

Immink, R. G. H., Ferrario, S., Busscher, L. J., Kooiker, M., Busscher, M. and Angenent, G. C. (2003). Analysis of the petunia MADS-box transcription factor family. Mol. Gen. and Genom.268: 598-606.

Källberg, M., Wang, H., Wang, S., Peng, J., Wang, Z., Lu, H. and Xu, J. (2012). Template-based protein structure modeling using the RaptorX web server. Nat. Prot. 7:1511-1522.

Kaufmann, K., Melzer, R. and Theißen, G. (2005). MIKC-type MADS-domain proteins: structural modularity, protein interactions and network evolution in land plants. Gene.347: 183-198.

Kelley, L.A., Mezulis, S., Yates, C.M., Wass, M.N.and Sternberg, M.J. (2015). The Phyre2 web portal for protein modeling, prediction and analysis. Nat Protoc. 10:845-58

Kwantes, M., Liebsch, D. and Verelst, W. (2012). How MIKC* MADS-box genes originated and evidence for their conserved function throughout the evolution of vascular plant gametophytes. Mol. Bio. And Evol. 29:293-303.

Lee, H., Suh, S.S., Park, E., Cho, E., Ahn, J.H., Kim, S.G., Lee, J.S., Kwon, Y.M. and Lee, I. (2000). The AGAMOUS-LIKE 20 MADS domain protein integrates floral inductive pathways in Arabidopsis. Genes Dev. 14: 2366-2376.

Lee, J. (2010). Regulation and function of SOC1, a flowering pathway integrator.J. Exp. Bot. 61: 2247-2254.

Lee, S., Kim, J., Han, J.J., Han, M.J. andAn, G. (2004). Functional analyses of the flowering time gene OsMADS50, the putative SUPPRESSOR OF OVEREXPRESSION OF CO 1/AGAMOUS-LIKE 20 (SOC1/AGL20) ortholog in rice. Plant J.38: 754-764.

Leseberg, C.H., Li, A., Kang, H., Duvall, M. and Mao, L. (2006). Genome-wide analysis of the MADS-box gene family in Populus trichocarpa. Gene. 
378: 84-94.

Li, C., Wang, Y., Xu, L., Nie, S., Chen, Y., Liang, D., Sun, X., Karanja, B.K., Luo, X. and Liu, L. (2016). Genomewide characterization of the MADSBox gene family in Radish (Raphanus sativus L.) and assessment of its roles in flowering and floral organogenesis. Front. Plant Sci. 7: 1390.

Lin, C.S., Hsu, C.T., Liao, C., Chang, W.J., Chou, M.L., Huang, Y.T., Chen, J.J., Ko, S.S., Chan, M.T. and Shih, M.C. (2015). Transcriptome-wide analysis of the MADS-box gene family in the orchid Erycinapusilla.Plant Biotechnol. J.14: 635-651.

Ma, G., Ning, G., Zhang, W., Zhan, J., Lv, H. and Bao M. (2011). Overexpression of Petunia SOC1-like gene FBP21 in tobacco promotes flowering without decreasing flower or fruit quality. Plant Mol. Biol. Rep. 29: 573-581.

Melzer, S., Lens, F., Gennen, J., Vanneste, S., Rohde, A. and Beeckman, T. (2008). Flowering-time genes modulate meristem determinacy and growth form in Arabidopsis thaliana. Nat. Genet. 40: 1489-1492.

Napoli, C., Lemieux, C. and Jorgensen, R. (1990). Introduction of a Chimeric Chalcone Synthase Gene into Petunia Results in Reversible Co-Suppression of Homologous Genes in trans. The Plant Cell. 2:279-289.

Norman, C., Runswick, M., Pollock, R. and Treisman, R. (1988). Isolation and properties of cDNA clones encoding SRF, a transcription factor that binds to the c-fos serum response element. Cell. 55: 989-1003.

Parenicová, L., De, F.S., Kieffer, M.,Horner, D.S., Favalli, C., Busscher, J., Cook, H.E., Ingram, R.M., Kater, M.M. and Davies, B. (2003). Molecular and Phylogenetic Analyses of the Complete MADS-Box Transcription
Factor Family in Arabidopsis: New Openings to the MADS World. Plant Cell. 15: 1538-1551.

Passmore, S., Maine, G.T., Elble, R., Christ, C. and Tye, B.K. (1988). Saccharomyces cerevisiae protein involved in plasmid maintenance is necessary for mating of MAT alpha cells. J. Mol. Biol. 204: 593-606.

Preston, J.C., Jorgensen, S.A. and Jha S.G. (2014).Functional Characterization of Duplicated Suppressor of Overexpression of CONSTANS 1-like genes in Petunia. PLOS ONE. 9: e96108.

Samach, A., Onouchi, H., Gold, S.E., Ditta, G.S., Schwarz-Sommer, Z., Yanofsky, M.F., Coupland, G. (2000). Distinct roles of COSTANS target genes in reproductive development of Arabidopsis. Sci. 288:1613-1616.

Sambrook, J.F. and Russell, D.W. (2001). Molecular Cloning: A Laboratory Manual, 3rd edn. Cold Spring Harbor Laboratory Press. 1, 2, 3:2100.

Shu, Y., Yu, D., Wang, D.,Guo, D. andGuo, C. (2013).Genome-wide survey and expression analysis of the MADS-box gene family in soybean. Mol. Biol. Rep. 40: 3901-3911.

Smaczniak, C., Immink, R. G., Angenent, G. C. and Kaufmann, K. (2012). Developmental and evolutionary diversity of plant MADS-domain factors: insights from recent studies. Develop. 139: 3081-3098.

Sommer, H., Beltran, J. P., Huijser, P., Pape, H., Lonnig, W. E., Saedler, H. and Schwarz-Sommer, Z. (1990). Deficiens, a homeotic gene involved in the control of flower morphogenesis in Antirrhinum majus: The protein shows homology to transcription factors. EMBO J.9: 605-613.

Sun. Y., Fan, Z., Li, X., Li, J. and Yin, H. (2014). The APETALAl and 
FRUITFUL homologs in Camellia japonica and their roles in doubleflower domestication. Mol. Breed. 33:821-834.

Tang, M., Tao, Y.B. andXu, Z.F. (2016). Ectopic expression of Jatropha curcas APETALA1 (JcAPl) caused early flowering in Arabidopsis, but not in Jatropha. Peer J. 4:e1969.

Theißen, G. and Gramzow, L. (2016). Structure and evolution of plant MADS domain transcription factors. In Plant Transcription Factors: Evolutionary, Structural and Functional Aspects (ed. D. H. Gonzalez) 127-138. Philadelphia: Elsevier.

Tian, Y., Dong, Q., Ji, Z., Chi, F., Cong, P. and Zhou, Z. (2015).Genome-wide identification and analysis of the MADS-box gene family in apple. Gene. 555: 277-290.
Xu, Z., Zhang, Q., Sun, L., Du, D., Cheng, T., Pan, H., Yang, W. and Wang, J. (2014).Genome-wide identification, characterisation and expression analysis of the MADS-box gene family in Prunus mume. Mol. Genet. Genom. 289: 903-920.

Yanofsky, M. F., Ma, H., Bowman, J. L., Drews, G.N., Feldmann, K.A. and Meyerowitz, E.M. (1990). The protein encoded by the Arabidopsis homeotic gene AGAMOUS resembles transcription factors. Nat. 346: 35-39.

Zhang, X., Wang, Q., Yang, S., Lin, S., Bao, M., Bendahmane, M., Wu, Q., Wang, C. and $\mathrm{Fu}, \mathrm{X}$. (2018). Identification and Characterization of the MADSBox Genes and Their Contribution to Flower Organ in Carnation (Dianthus caryophyllus L.).Genes. 9:193.

\section{How to cite this article:}

Shilpy Singh, Vivek Rana, Pushpendra Kumar, Manoj Kumar Yadav and Vaishali. 2019. Isolation and Expression Analysis of Floral Binding Protein 20 (FBP20) MADS Box Gene in Petunia axillaris. Int.J.Curr.Microbiol.App.Sci. 8(01): 1942-1955.

doi: https://doi.org/10.20546/ijcmas.2019.801.204 